\title{
Mapa de capacidade e potencial do uso da terra do município de Catalão (GO)
}

\author{
Map of capacity and land use potential of the municipality of Catalão (GO)
}

\author{
Antonio Santiago da Silva \\ Mestre em Geografia. Universidade Federal de Uberlândia, IG, Prograd, Uberlândia, MG \\ asantiagogeo@gmail.com
}

Roberto Rosa

Doutor em Geografia. Universidade Federal de Uberlândia, Instituto de Geografia, Uberlândia, MG

$\underline{\text { rrosa@ufu.br }}$

Artigo recebido para revisão em 15/02/2019 e aceito para publicação em 13/07/19

\begin{abstract}
Resumo
O estudo tem como objetivo produzir um mapa de uso potencial das terras no município de Catalão (GO). A organização e a análise dos dados extraídos dos mapas temáticos, as informações coletadas em campo e as fontes documentais auxiliaram na produção e na proposição de um mapa de uso potencial da terra do município, conforme suas características físico-naturais. Deste modo, utilizouse nos procedimentos operacionais, a metodologia para as pesquisas geográficas, em quatro níveis (ou etapas): o compilatório, o correlatório, o semântico e o normativo. Foram usados para a realização desse trabalho cartas imagem 1:100.000 do IBGE e imagens OLI/Landsat8, ALOS PALSAR, dentre outros. No software QGIS e nos módulos de algoritmos nele presentes, foram elaborados mapas de declividade, de hipsometria, de capacidade de uso da terra e de seu uso potencial. As terras classificadas no mapa de capacidade de uso das terras mostraram que as classes I, II e III, equivalente a $69,85 \%$ da área da pesquisa estão aptas para a agricultura desde que resguardadas as de áreas de preservação permanente. As terras de classe IV representam 3,64\% do total de área e têm limitações que são ainda mais severas para cultivos. Já as terras classe VI, com $13,12 \%$ da área, são recomendadas para pastagens e reflorestamento. As de classe VII são indicadas para reflorestamentos, contando com 2,83\% do total da área. As terras da classe VIII são indicadas para a fauna e flora, totalizando 5,34\%. Por fim, o mapa de uso potencial das terras elaborado considerou as potencialidades dos recursos naturais, as fragilidades dos sistemas ambientais naturais e a recuperação dos ambientes degradados. As classes de uso potencial das terras no município de Catalão mostram que do total das terras recomendadas, 40,69\% são para a agricultura, 11,84\% para pastagens, 3,32\% para reflorestamento e $38,33 \%$ para preservação.
\end{abstract}

Palavras-chave: Uso potencial das terras; Geoprocessamento; SIG; Software livre; QGIS.

\begin{abstract}
The study aims to produce a map of potential land use in the city of Catalão (GO) in Brazil. The organization and analysis of the data extracted from the thematic maps, the information collected in the field and documentary sources helped in the production and the proposal of a map of potential use of the land of the city according to its physical-natural characteristics. Thus, in the operational procedures, the methodology for geographic research was used in four levels (or stages): the compiling, the correlative, the semantic and the normative. These images were used to carry out this research: image 1: 100,000 from IBGE and OLI / Landsat8 images, ALOS PALSAR, among others. In the QGIS software and in the algorithm modules in it, maps of declivity, hypsometry, land use
\end{abstract}


capacity and their potential use were elaborated. The lands classified in the map land use capacity showed that classes I, II and III, equivalent to $69.85 \%$ of the research area are suitable for agriculture restraining to those in areas of permanent preservation. Class IV lands represent 3.64\% of the total area, with limitations that are even more severe for crops. Class VI land with $13.12 \%$ of the area is recommended for pasture and reforestation. Class VII is indicated for reforestation accounts for $2.83 \%$ of the total area. The lands of class VIII are indicated for the fauna and flora with $5.34 \%$. Finally, the potential land use map elaborated considered the potential of natural resources, the fragilities of natural environmental systems, and the recovery of degraded environments. Potential land use classes in the city of Catalão show that of the total land recommended, $40.69 \%$ is for agriculture, $11.84 \%$ for pasture, $3.32 \%$ for reforestation and $38.33 \%$ for preservation.

Keywords: Potential land use; Geoprocessing; GIS; Free software; QGIS.

\section{INTRODUÇÃO}

A crescente demanda por recursos naturais gerada pelo sistema socioeconômico capitalista promove um cenário em que os diversos ecossistemas brasileiros vêm sofrendo uma grande degradação causada pela intensa exploração e falta de planejamento. Desse modo, o Bioma Cerrado, o segundo maior do Brasil, encontra-se em um estágio de antropização acelerado. O Bioma, que ocupa quase todo o estado de Goiás, teve um percentual de $57 \%$ de suas áreas de cobertura vegetal natural alteradas por diversos usos.

Klein (1996) e Ferreira (2003) são consoantes em suas afirmações de que o visível uso inadequado, agrícola e não-agrícola, dos recursos hídricos, do solo e da vegetação do Cerrado resulta em degradação ambiental de vários tipos: erosão, assoreamento, exaustão dos solos, poluição dos mananciais, afogamento e migração de nascentes, perda de biodiversidade, além de destruição das matas ciliares.

Certamente, é urgente a necessidade de mais estudos e análises da paisagem do Cerrado, por ela ser "uma herança em todo o sentido da palavra: é herança de processos fisiográficos e biológicos e patrimônio coletivo dos povos que historicamente o herdaram como território de suas comunidades" (AB'SABER, 2003, p. 9). Segundo o Mapeamento do Uso e Cobertura do Cerrado (BRASIL, 2015), o projeto TerraClass mostra que as Unidades de Conservação cobrem somente 8,6 \% da paisagem natural do Cerrado.

O Sistema de Aptidão da Terra (SAA) e o Sistema de Capacidade de Uso (SCU) são importantes técnicas para o planejamento do uso da terra porque tornam possível medir a dinâmica dos impactos em determinado espaço ou ecossistema. Por meio deles pode-se definir o potencial da terra, a limitação e o manejo adequado. Com a utilização destes sistemas, estabelecem-se alternativas possíveis, pois, conforme pontuaram Assad, Hamada e Cavalieri (1998), são necessárias medidas e recursos para determinar a capacidade do meio de suportar os impactos decorrentes do manejo. O sistema de 
capacidade de uso de Lepsch et al. (2015) já está na sua quinta aproximação por ser considerado melhor para conservação compatível com as informações sobre solos disponíveis para pesquisa, conforme Assad, Hamada e Cavalieri (1998), Brito (2001) e Mendes (2016).

Nesse sentido, frente a tantos reordenamentos espaciais na paisagem do Cerrado, a incorporação de metodologias de geoprocessamento é necessária e positiva para se fazer mapeamentos com qualidade, utilizando-se aparatos compatíveis e de baixo custo. Para conhecer melhor o espaço geográfico, é importante realizar o diagnóstico e o planejamento do uso potencial da terra. Trabalhos dessa temática podem ser verificados em Brito (2001), Mendes (2016), Silva, Gusson e Rosa (2017) e Silva (2018). No contexto delineado, o objetivo desta pesquisa é produzir um mapa de uso potencial das terras, de acordo com as características físico-naturais do município de Catalão (GO).

A área de pesquisa, o município de Catalão, situa-se no Sudeste Goiano e está compreendida entre os meridianos de $47^{\circ} 17^{\prime}$ e $48^{\circ} 12^{\prime}$ Longitude Oeste de Greenwich e os paralelos $17^{\circ} 28^{\prime}$ e $18^{\circ} 30^{\prime}$ Latitude Sul, abrangendo 3.821,463km² (IBGE, Resolução nº PR-02, de 29/06/2017), conforme Figura 1.

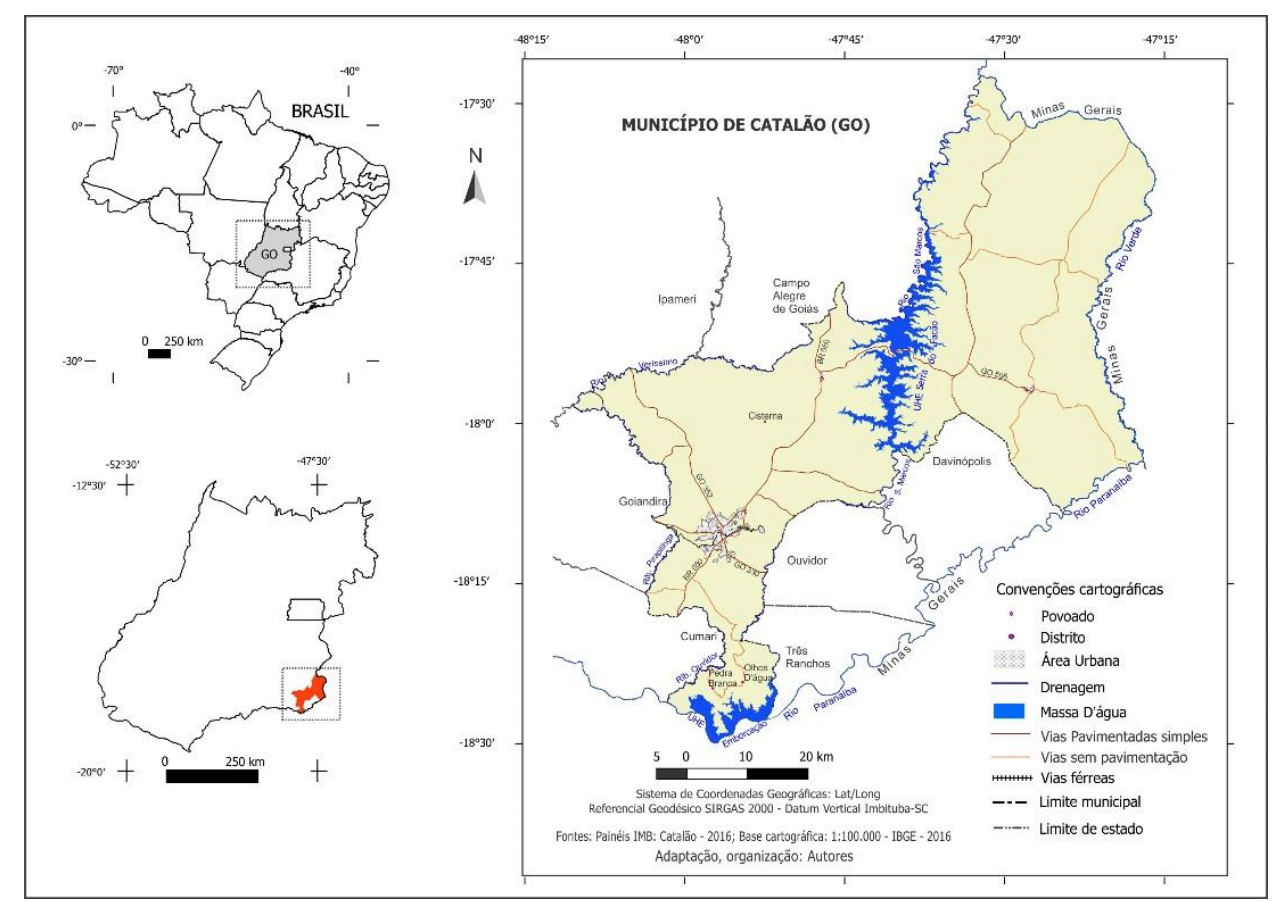

Figura 1 - Mapa de localização do município de Catalão (GO).

Fonte: Elaboração dos autores (2018).

A Cidade de Catalão possui três povoados: Olhos D’água, Pedra Branca, Cisterna, e dois distritos: Santo Antônio do Rio Verde e Pires Belo. O município de Catalão conta com 86.647 habitantes, de acordo com o Censo Demográfico dos Municípios do Estado de Goiás (IBGE, 2010). Segundo estimativas, a população em 2018 é de 106.618 habitantes (IBGE, 2018).

O município de Catalão situa-se inserido no Bioma Cerrado, que foi atingido pela expansão da fronteira agrícola, subsidiada pelo Estado. Tal expansão foi iniciada no final dos anos de 1950 e 
ampliada nos anos de 1970, a partir de políticas de modernização da agricultura e da pecuária, o que, consequentemente, promoveu a instalação da agroindústria, impulsionando a produção de commodities no setor. Também, de acordo com Mendes (2005), na década de 1970, houve a instalação de mineradoras de nióbio e de fosfato e, em seguida, com a criação do Distrito Mínero-Industrial (DIMIC), a instalação das montadoras de veículos e máquinas agrícolas. Em Catalão (GO), ainda foram construídas duas usinas hidrelétricas: a da Emborcação, no início dos anos 1980, e, mais recentemente, a da Serra do Facão.

O clima de Catalão, conforme a classificação de Köppen é do tipo tropical. No inverno ocorre menor pluviosidade que no verão. Segundo Köppen e Geiger (1954), o clima do município é classificado como Aw. Dados do Instituto Nacional de Meteorologia (INMET), publicados em 2018, mostram que a temperatura média de Catalão é de $23^{\circ} \mathrm{C}$ e a pluviosidade média anual é de 1449,6 mm. Numa comparação entre o mês mais seco e o mais chuvoso, há uma diferença de precipitação de 277,6 mm. Já a temperatura média do mês de fevereiro: é a mais alta do ano, sendo de $23,9^{\circ} \mathrm{C}$. No mês julho, a temperatura média é $20,20^{\circ} \mathrm{C}$. O mês mais seco é julho com $5,3 \mathrm{~mm}$ de precipitação. O maior índice de precipitação ocorre em janeiro, com uma média de 282,9 $\mathrm{mm}$.

O município de Catalão tem a geologia bem diversificada. Situa-se na Faixa Brasiliana, que está localizada entre o Cráton São Francisco e os Domínios Goiano e Araí-Natividade, conforme Hasui et al. (2012); está inserida no Sistema Orogênico Tocantins. Catalão, conforme o Macrozoneamento Agroecológico e Econômico do Estado de Goiás (MACROZAEE-GO, 2014), comporta unidades metassedimentares da Era Mesoproterozoica, o Grupo Canastra - Formação Chapada dos Pilões (MPcp), da Era Neoproterozoica, as unidades metavulcanossedimentares do Grupo Araxá (NPaa) e o Grupo Araxá - Unidade A - litofácies hematita, xisto (NPaahx), o Grupo Rio Veríssimo, a classe Sequência metavulcanossedimentar Rio Veríssimo (NPvsrv), unidades granitoides gnaissificadas. Abrange também, a Unidade máfico-ultramáfica Complexo alcalino Catalão I e II (K2), o Grupo Ibiá Formação Cubatão e o grupo Ibiá - Formação Rio Verde, Formação Cubatão (NPcb), Formação Rio Verde (NPrv), Coberturas detrito-lateríticas ferruginosas (N1dl), a Suíte Jurubatuba (PP2) e os depósitos aluvionares.

A Geomorfologia da área de estudo apresenta as classes de Planaltos e Chapadas Goiás-Minas que, em sua subdivisão dissecação homogênea tabular (Dt), a subdivisão pediplano degradado inumado (Pgi), as Superfícies Aplanadas, com dissecação homogênea convexa (Dc). E o Planalto Central Goiano, em sua subdivisão dissecação estrutural (De). A máxima altitude registrada na área foi de 960m, numa área plana de chapada. Os pontos de maior altitude estão localizados no nordeste do município, representados por Coberturas detrito-lateríticas ferruginosas e Grupo Canastra - Formação Chapada dos Pilões. Nos chamados vales fluviais estão as altitudes mais baixas, que oscilam em torno dos 520-560 metros. O ponto mais baixo de Catalão é a calha do rio Paranaíba, na parte sul do 
município. Conforme, Ferreira (2003), podem ser constatadas ainda formas residuais no referido pediplano, como paleoinselbergs individualizados nos Morros da Saudade e das Três Cruzes, na cota de 960 metros.

Catalão (GO) situa-se na bacia hidrográfica do rio Paranaíba, que possui rio de mesmo nome, localizado ao centro-leste e sul do município, fazendo limite com o estado de Minas Gerais. Nesta mesma bacia hidrográfica estão os principais rios que drenam a região e a área de pesquisa; ao centro do município, destaca-se o rio São Marcos, que possui múltiplos usos, entre eles o barramento da UHE Serra do Facão e Paulistas já nos municípios de Ipameri (GO) e Cristalina (GO). Na região denominada Chapadão de Catalão, à margem esquerda do rio São Marcos, situa-se o rio São Bento, que possui grande importância para a manutenção da fauna e da flora e que concentra maior parte de ambiente de vereda, sendo muito utilizado para irrigação por pivôs centrais para monoculturas diversas. Já na divisa com Minas Gerais, localiza-se o rio Verde. O município possui outros rios de relevância hídrica como, por exemplo, o Veríssimo, a oeste do município na divisa com Ipameri, e ainda os ribeirões Pirapitinga, que nasce na área urbana de Catalão e os ribeirões Samambaia e Pari, ambos utilizados para captação de água para abastecimento público do município.

A vegetação característica do município de Catalão é o Cerrado, que engloba outros tipos de vegetação como a florestal, a savânica e a campestre. Com a elaboração do mapa de solos da área de estudo, constatou-se que o município de Catalão conta com cinco classes de solo predominantes: Argissolos, Cambissolos, Latossolos, Neossolos e Gleissolos.

\section{MATERIAIS E MÉTODOS}

O desenvolvimento desta pesquisa utilizou procedimentos metodológicos operacionais para orientar as etapas da pesquisa, que se baseia em Libault (1971), que prevê metodologia para as pesquisas geográficas em quatro níveis (ou etapas): o compilatório, o correlatório, o semântico e o normativo. Para melhor compreensão da metodologia utilizada para realizar procedimentos e para contemplar o objetivo da pesquisa, sigo etapas de processamento e análise utilizadas por Rosa (1995), Brito (2001), Ross (2001) e Silva (2018), conforme Figura 2. 


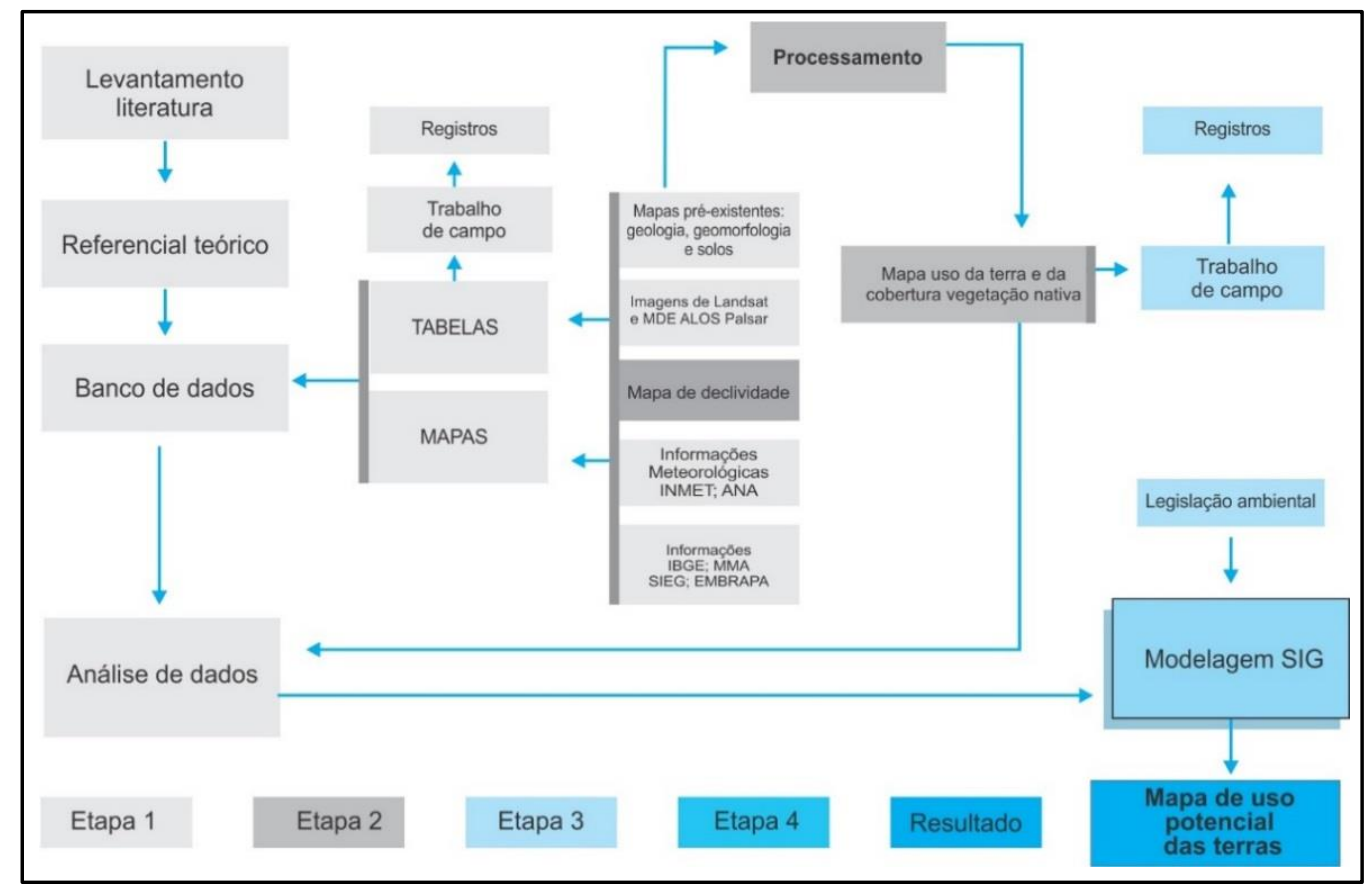

Figura 2 - Etapas de processamento e análise. Fonte: Elaboração dos autores (2017).

$\mathrm{F}$

Desse modo, foram levantados e organizados informações e procedimentos de fontes referentes ao tema da pesquisa, contemplando dados não espaciais e espaciais, obtendo dados e bases cartográficas para realização do mapa de uso potencial da terra, composto pelo cruzamento dos mapas declividade, solo e mapas de uso da terra e cobertura vegetal nativa e APPs. O mapa das APPs foi elaborado conforme descrição da Lei $n^{\circ}$ 12.651/2012, Resolução Conama 302/2002 e 303/2002 (BRASIL, 2002a; BRASIL, 2002b) e o mapa de uso da terra e cobertura vegetal nativa, ambos conforme procedimentos metodológicos operacionais, conforme detalhou Silva (2018).

Para desenvolver este trabalho foi necessário a construção de um banco de dados cartográficos utilizados na pesquisa, como descrito a seguir:

- Cartas Imagem na escala de 1:100.000 UTM, Referencial Geodésico SIRGAS2000, Datum vertical Imbituba: SE.23-V-C-I; SE.23-V-C-IV; SE.22-X-D-VI; SE.23-Y-A-I; SE.22-Z-B-III; SE-23-VC-V; SE-23-Y-A-II, 2011 - IBGE. Articulação das cartas foram utilizadas para realizar correção geométrica das imagens de satélites.

- Base cartográfica do arquivo gráfico municipal na escala de 1:100.000 - 2016 - IBGE, utilizando vetores da hidrografia e da malha viária.

- Imagens de radar da Agência Japonesa de Exploração Aeroespacial, JAXA, ALOS PALSAR, L-Band, Polarização HH com resolução de 12,5 metros, Bandas ALPSRP dos meses de fevereiro e março de 2011, no catálogo Vertex do Alasca Satellite Facility (ASF), disponibilizadas gratuitamente em (vertex.daac.asf.alaska.edu), (NOAA), (ESA), Geoscience Australia e JAXA. Foram utilizadas para elaborar os mapas de hipsometria e de declividade, obtida por MDE 12,5 metros, depois 
gerado MDT diretamente através do Plugin PKtools - Processing Kernel for geospatial data, conforme Silva (2018).

- Mapa de Solos e perfis no formato vetor, folhas SE.22 e SE.23, ambos no recorte de 1:250.000, do Projeto RADAMBRASIL, atualizados conforme Manual Técnico de Pedologia (IBGE, 2015); refinamento de solos de Goiás para a escala de 1:250.000, Emater (2016), depois de compilados foram recortados e adaptados para o mapa de solo da pesquisa.

- Imagens do Sensor OLI/Landsat 8, bandas espectrais do visível e infravermelho próximo, imagem falsa-cor RGB (564 vegetação vermelha), bandas 4 (região do vermelho, 0,64 - 0,67 $\mu \mathrm{m}$ ), 5 (infravermelho próximo, 0,85 - 0,88 $\mu \mathrm{m}$ ) e 6 (região do infravermelho de ondas curtas, 1,57- 1,65 $\mu \mathrm{m}$ ), dos meses de julho a setembro de 2016, disponibilizadas pelo Departamento de Geologia dos Estados Unidos USGS - EROS Center (earthexplorer.usgs.gov), utilizadas para elaborar o mapa de uso da terra e cobertura vegetal nativa. O processo de vetorização contemplou a construção de chaves de interpretação, como a cor ou tonalidade, textura, tamanho, forma e mesa digitalizadora multi-touch Wacom Intuos Pro, 320 x 208 x 12 mm, caneta com 2048 níveis de sensibilidade à pressão.

A compilação, a edição e a elaboração dos produtos cartográficos foram realizadas nos softwares livres QGIS 2.14 Essen e 2.18 Las Palmas, utilizados em todos mapas da pesquisa, para elaboração do banco de dados geográficos, vetorização e análises espaciais. O GRASS GIS 7.2 foi utilizado para análises espaciais para quantificar as classes por área dos mapas propostos e para gerar as classes de declividade por fatiamento com critérios adaptados de Embrapa (1979) e de Lepsch et al. (2015). O Gimp 2.8 foi utilizado para auxiliar na vetorização de imagens Landsat8 com o plugin ou módulo de extensão do QGIS, Gimp Selection Feature desenvolvido por Motta (2017); Já o Inkscape 0.91 foi utilizado para finalizar os layouts dos mapas exportados do QGIS.

Foram realizados diversos trabalhos de campo para conferência das informações mapeadas, dos tipos de solos, dos usos e ocupações da terra, confirmando as interpretações das imagens de satélite e do georrefereciamento das imagens com suporte de GPS (Sistema de Posicionamento Global de Navegação) Garmin com registro de pontos coletados e fotografados.

Para a obtenção do mapa de capacidade de uso das terras até subclasse, foram necessários e foram realizados cruzamentos para analisar a distribuição nos diferentes compartimentos do meio físico, entre eles componentes da fórmula mínima, o mapa de solo, o mapa de declividade e tabulações, conforme procedimentos propostos por Lepsch et al. (1991; 2015). O Quadro 1 traz o resumo dos critérios utilizados para obtenção das classes de capacidade de uso, solos, declividade e grau de fragilidade à erodilidade (Ross, 2012). 
Quadro 1 - Critérios para obtenção das classes de capacidade - 2017.

\begin{tabular}{|c|c|c|c|c|}
\hline Tipo de solo & Classes & $\begin{array}{l}\text { Sub- } \\
\text { classe }\end{array}$ & $\begin{array}{l}\text { Grau de fragilidade } \\
\text { à erodilidade }\end{array}$ & $\begin{array}{c}\text { Declividade } \\
\text { Adap. Embrapa* }\end{array}$ \\
\hline ARGISSOLO VERMELHO-AMARELO & II 1,2 & IIe & \multirow{3}{*}{ Médio } & \\
\hline \multirow[t]{2}{*}{ Eutrófico - PVAe } & IV $3,4,5$ & IVe & & \\
\hline & II 1,2 & IIe & & \\
\hline \multirow[t]{3}{*}{ CAMBISSOLO HÁPLICO Alumínico - CXa } & III 3 & IIIe & \multirow[t]{3}{*}{ Forte } & \\
\hline & IV 4,5 & IVe & & \\
\hline & II 1,2 & IIe & & \\
\hline \multirow[t]{2}{*}{ CAMBISSOLO HÁPLICO Tb Distrófico - CXbd } & III 3 & IIIe & \multirow[t]{2}{*}{ Forte } & \\
\hline & IV 4,5 & IVe & & \\
\hline \multirow{3}{*}{$\begin{array}{l}\text { LATOSSOLO VERMELHO-AMARELO } \\
\text { Distrófico - LVAd }\end{array}$} & II 1,2 & $\begin{array}{l}\text { II } \\
\text { IIe }\end{array}$ & \multirow{3}{*}{ Muito Fraco } & \\
\hline & III 3 & IIIe & & \\
\hline & IV 4 & IVe & & \\
\hline \multirow{4}{*}{ LATOSSOLO VERMELHO Distrófico - LVd } & II 1 & II & \multirow{4}{*}{ Muito Fraco } & $1-<3$ \\
\hline & II 2 & IIe & & $2-3-8$ \\
\hline & III 3 & IIIe & & $3-8-20$ \\
\hline & IV 45 & IVe & & $4-20-45$ \\
\hline \multirow{4}{*}{ LATOSSOLO VERMELHO Distroférrico - LVdf } & II 1 & II & \multirow{5}{*}{ Muito Fraco } & $5->45$ \\
\hline & II 2 & IIe & & \\
\hline & III 3 & IIIle & & \\
\hline & IV 4 & IVe & & \\
\hline \multirow{3}{*}{ LATOSSOLO VERMELHO Ácrico - LVw } & I 1 & I & & \\
\hline & II 2 & II & \multirow[t]{3}{*}{ Muito Fraco } & \\
\hline & $\begin{array}{l}\text { III } 3 \\
\text { VII } 4\end{array}$ & $\begin{array}{l}\text { IIIJe } \\
\text { VUIe }\end{array}$ & & \\
\hline \multirow{3}{*}{ NEOSSOLO LITÓLICO Distrófico - RLd } & VI1 $1,2,3$ & Vis & & \\
\hline & VII 4 & VIIe & \multirow[t]{2}{*}{ Muito Forte } & \\
\hline & VIII 5 & VIIIIe & & \\
\hline \multirow{2}{*}{$\begin{array}{l}\text { Cambissolo Háplico Tb Distrófico - CXbd + } \\
\text { GLEISSOLO HÁPLICO Tb - GXbd }\end{array}$} & VII 3,4 & VIIIa & \multirow{2}{*}{ Forte a Muito Forte } & \\
\hline & VIIII 1,2 & VIIe & & \\
\hline
\end{tabular}

* Os números de 1-5 das colunas Declividade, relevo declividade adaptado pela Embrapa Classe referem-se aos intervalos e declividade $1=<3 ; 2=3-8 ; 3=8-20 ; 4=20-45 ; 5=>45$

Fontes: Lepsch et al. (1991; 2015), Embrapa (1979); Santos et al. (2013); Ross (2012).

Organização: Autores (2018).

Para realizar o cruzamento utilizando critérios sintetizados no Quadro 1, utilizou-se as expressões com operadores para viabilizar as análises espaciais por meio da calculadora de dados raster no QGIS. A seguir está um exemplo de sintaxe utilizada com operadores Boleanos de intersecção da declividade e solos criando as classes de capacidade de uso III:

( "solosr@1" = 3 AND "decliv_f@1"=3 )+ ( "solosr@1" = 4 AND "decliv_f@1" = 3 )+ ( "solosr@1" = 5 AND "decliv_f@1" = 3) + ("solosr@1" =6 AND "decliv_f@1" = 3 ) + ( "solosr@1" = 7 AND "decliv_f@1" = 3 ) + ("solosr@1" = 8 AND "decliv_f@1" = 3 )

Logo em seguida, cada classe de capacidade foi reclassificada, utilizando-se o módulo GRASS GIS r.recode; para isso, foi criado um arquivo .txt com a expressão de intervalos das classes, obtendo-se a capacidade de cada classe e numerada e nan (vazio), para em seguida, unir-se as classes das capacidades através do módulo GDAL/OGR > Mesclar > Camadas de entrada > Run, gerando o mapa de capacidade de uso. 
Já o mapa de uso potencial da terra foi elaborado através do cruzamento dos mapas de declividade, solo e mapas de uso da terra e cobertura vegetal nativa e de APPs; ou seja, primeiramente foi realizado o cruzamento do mapa de declividade com o mapa de solo e, depois, o mapa de capacidade com o de uso da terra e APPs, conforme ilustra a Figura 3.

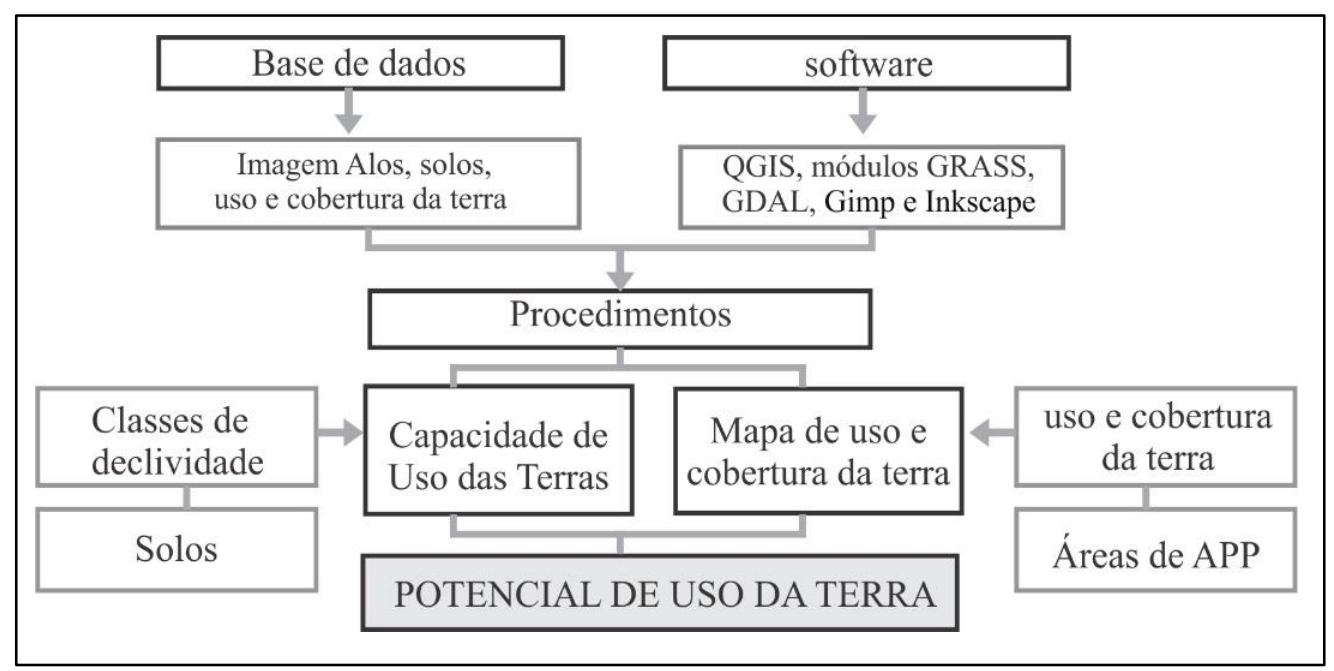

Figura 3 - Esquema das etapas para geração do mapa de potencial uso da terra

Fonte: Elaboração dos Autores (2018)

Por conseguinte, antes de realizar o cruzamento do mapa de capacidade de uso com o de uso da terra e APPs, as classes do mapa de capacidade foram transformadas em polígonos no modulo GRASS, e em seguida por meio da seguinte sequência: QGIS>ferramenta de geoprocessamento> recorte > diferença, para cada classe de mapa. Esse procedimento foi realizado um por vez a cada classe do mapa de capacidade de uso com o mapa de uso da terra e APPs, após o término foram unidas, utilizando-se a sequência: QGIS>menu vetor gerenciar dados > mesclar shapes, obtendo-se com isso o mapa de uso potencial da terra do município. Em seguida, as áreas do mapa de uso potencial da terra foram rasterizadas e quantificadas.

\section{RESULTADOS E DISCUSSÃO}

Para determinar o potencial da terra de uma área, foi necessário elencar aspectos de solos, declividade, uso da terra, APPs e a capacidade de uso, conforme o Sistema de Capacidade de Uso (SCU) no intuito de obter o melhor aproveitamento dos solos.

Após compilar e adaptar o mapa de solos da área de estudo, constatou-se que o município de Catalão conta com cinco classes de solo predominantes: argissolos, cambissolos, latossolos, neossolos e gleissolos (Figura 4). O Quadro 2 traz as classes de solos presentes no município de Catalão dadas por quilômetro quadrado, hectare e porcentagem. 
Quadro 2 - Área das classes de solos do município de Catalão.

\begin{tabular}{lrrr}
\hline \multicolumn{1}{c}{ Classes litológicas } & \multicolumn{2}{c}{ Área } & \multicolumn{1}{c}{ Km } \\
\hline ARGISSOLO VERMELHO-AMARELO Eutrófico - PVAe & 246,32 & $24.748,38$ & 6,45 \\
CAMBISSOLO HÁPLICO Alumínico - CXa & 153,83 & $15.499,17$ & 4,04 \\
CAMBISSOLO HÁPLICO Tb Distrófico - CXbd & 741,51 & $74.267,46$ & 19,37 \\
LATOSSOLO VERMELHO-AMARELO Distrófico - LVAd & 633,65 & $63.481,95$ & 16,56 \\
LATOSSOLO VERMELHO Distrófico - LVd & 958,30 & $95.946,21$ & 25,02 \\
LATOSSOLO VERMELHO Distroférrico - LVdf & 16,81 & 1797,21 & 0,47 \\
LATOSSOLO VERMELHO Ácrico - LVw & 58,91 & 6007,23 & 1,57 \\
NEOSSOLO LITÓLICO Distrófico - RLd & 535,67 & $53.683,65$ & 14,00 \\
CAMBISSOLO HÁPLICO Tb Distrófico - CXbd + & 278,40 & $27.955,98$ & 7,29 \\
GLEISSOLO HÁPLICO Tb - GXbd & 22,10 & 2326,68 & 0,61 \\
Urbano & 175,97 & $17.713,53$ & 4,62 \\
Massa D’água & $3.821,463$ & $383.427,45$ & 100,00 \\
\hline Total & & &
\end{tabular}

Fonte: Mapa de solos 2017, compilado, adaptado dos recortes das Folhas SE.23 e SE.22, escala 1:250.000, Radambrasil (2016).

Elaboração: Elaboração dos autores (2017).

No mapeamento dos solos mostra-se a classe ARGISSOLO VERMELHO-AMARELO Eutrófico - PVAe, típico, com textura média, muito cascalhenta/argilosa cascalhenta, horizonte A moderado, e em relevo ondulado. Sua classe possui uma faixa à direita da área urbana de Catalão em direção à Comunidade Cisterna e ao sul próximo aos povoados de Olhos D'água e Pedra Branca, somando $6,45 \%$ de Catalão.

O CAMBISSOLO HÁPLICOS Alumínicos-Cxa, com textura média e argilosa cascalhenta, horizonte A moderado, em relevo forte ondulado e ondulado, ocupa 4,04\% do total da área do município e está concentrado na parte central do município de Catalão indo até o limite com o município de Campo Alegre de Goiás. Já o CAMBISSOLO HÁPLICOS Tb Distrófico - CXbd típico, de textura argilosa, média e argilosa cascalhenta, média cascalhenta, com horizonte A moderado, em relevo ondulado e forte ondulado, está distribuído da parte central do município até a borda do represamento do rio São Marcos e até o Domo catalão II e lado leste. Essa classe é a segunda maior área de solo do município, presente em 19,37\%, conforme Quadro 2.

Os Latossolos são solos que possuem características indicadas para uso intensivo com uso de maquinário agrícola; os perfis deste tipo de solo medem aproximadamente $150 \mathrm{~cm}$ e sua vegetação caraterística é o cerrado típico. O LATOSSOLO VERMELHO-AMARELO Distrófico - LVAd, típico, com textura argilosa e muito argilosa, horizonte A moderado, relevo plano e suave ondulado ocorre em 
16,56\% do total da área e se concentra no Chapadão de Catalão, conforme Figura 4. Já o LATOSSOLO VERMELHO Distrófico - LVd, típico, com textura argilosa e muito argilosa, horizonte A moderado, em relevo plano e suave ondulado, ocupa $25,02 \%$ do total de área, sendo o de maior percentagem.

O LATOSSOLO VERMELHO Distroférrico - LVdf, típico, com textura muito argilosa e argilosa, horizonte A moderado, em relevo suave ondulado, ocorre em 0,47\% da área do município, sendo o solo de menor ocorrência na pesquisa; seu uso atual consiste em maior proporção de mineração, pastagem e reflorestamento. Já o LATOSSOLO VERMELHO Ácrico - LVw, típico, representa 1,57\% da área e ocorre no lado leste de Catalão, limite com Goiandira. Possui textura argilosa, horizonte A moderado e relevo plano e suave ondulado.

A classe NEOSSOLO LITÓLICO Distrófico - RLd típico está presente em parte da margem esquerda do rio São Bento, a porção mais dissecada do Chapadão de Catalão, possui textura média cascalhenta, horizonte moderado e A fraco, em relevo forte ondulado e ondulado. Esses solos possuem maiores limitações quanto ao uso, ocupando $14 \%$ da área pesquisada área.

Já o CAMBISSOLO HÁPLICO Tb Distrófico típico, com textura media cascalhenta, horizonte A moderado e pedregoso, relevo suave ondulado e ondulado e o GLEISSOLO HÁPLICO Tb concentram-se no Chapadão de Catalão e juntos ocupam 7,29\% de toda a área pesquisada.

A classe CAMBISSOLO HÁPLICO Tb Distrófico se encontra nas bordas de áreas de vereda e o GLEISSOLO tem presença sob as veredas conforme Ferreira (2003). Confirmado em campo, nesse ambiente, os solos se encontram encharcados por água.

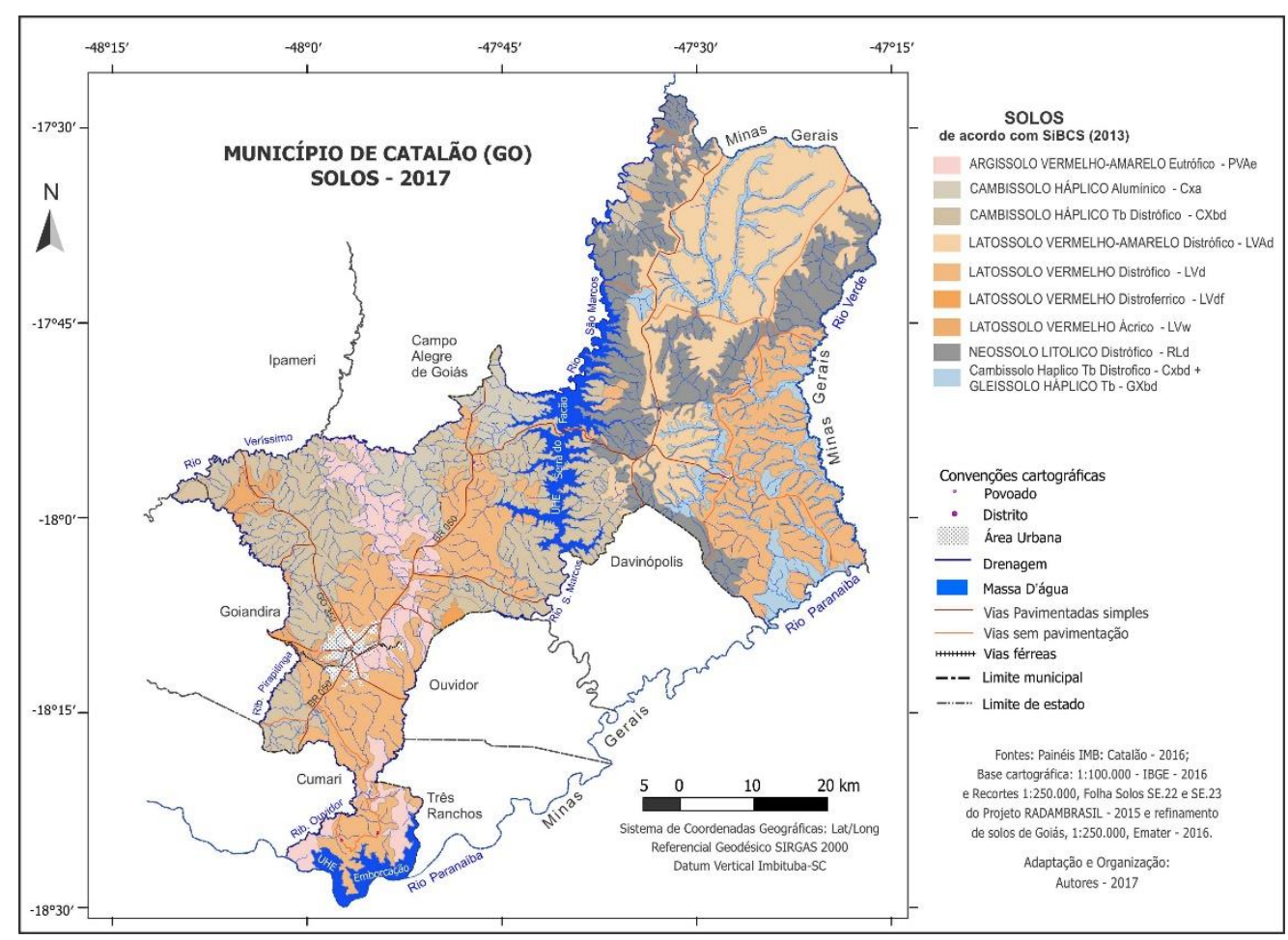

Figura 4 - Mapa de Solos do município de Catalão (GO) - 2017

Fonte: RADAMBRASIL (2016); Emater (2016)

Compilação, adaptação e organização: Autores (2017) 
O mapa de declividade foi obtido a partir de Imagens Alos 12,5m para identificar as APPs por declividade e topo de morro de acordo com a Lei 12.651/12. A proposta da Embrapa (2013) também foi comtemplada para definir as classes de declividade.

As declividades que predominam no município são as de relevo de dissecação Suave ondulado, intervalo 3-8, o que significa $42.19 \%$ da área do município e concentram-se na porção nordeste no município, na área de topo de chapada no intervalo de altitude 920-960m, conforme Figura 5 e Quadro 3.

Quadro 3 - Área dos intervalos de declividade no município de Catalão.

\begin{tabular}{|c|c|c|c|c|}
\hline \multirow{2}{*}{ Intervalos de declividade } & \multirow{2}{*}{$\begin{array}{l}\text { Intervalos de } \\
\text { declividade }\end{array}$} & \multicolumn{3}{|c|}{ Área } \\
\hline & & $\mathbf{K m}^{2}$ & Ha & $\%$ \\
\hline Plano & $<3$ & 951,32 & $95.132,04$ & 24,89 \\
\hline Suave ondulado & $3-8$ & $1.612,04$ & $161.203,98$ & 42,19 \\
\hline Ondulado & $8-20$ & $1.175,20$ & $117.520,07$ & 30,75 \\
\hline Forte ondulado & $20-45$ & 82,59 & $8.258,911$ & 2,15 \\
\hline Montanhoso & $>45$ & 0,31 & 31.287 & 0,01 \\
\hline Total & & $3.821,463$ & $382.146,300$ & 100,00 \\
\hline
\end{tabular}

Fonte: Mapa de declividade, 2017 e Proposta Embrapa (2013) adaptada.

Elaboração: Autores (2017).

Já o intervalo de declividade Plano, <3, são 24,89\%; os de Suave ondulado, 3-8, são 4,19\%; o intervalo de declividade Ondulado, 8 - 20, ocupando 30,75\% da área. Os intervalos de declividade Forte ondulado, 20-45, representam 2,15\%; o intervalo Montanhoso, > 45, é de apenas 0,01\%.

Quanto maior sua configuração, mais susceptíveis a processos erosivos, e se somado à característica declive elevado e à fragilidade natural dos solos, tem-se situação agravada. Mesmo nas áreas plantadas em relevo levemente acidentado e aplainados, deve-se ter devido cuidado no manejo quanto aos processos de escoamento superficial de fluxos de água espalhados e não canalizados (concentrados), podendo iniciar processos erosivos com laminar, evoluindo para ravinamento. 


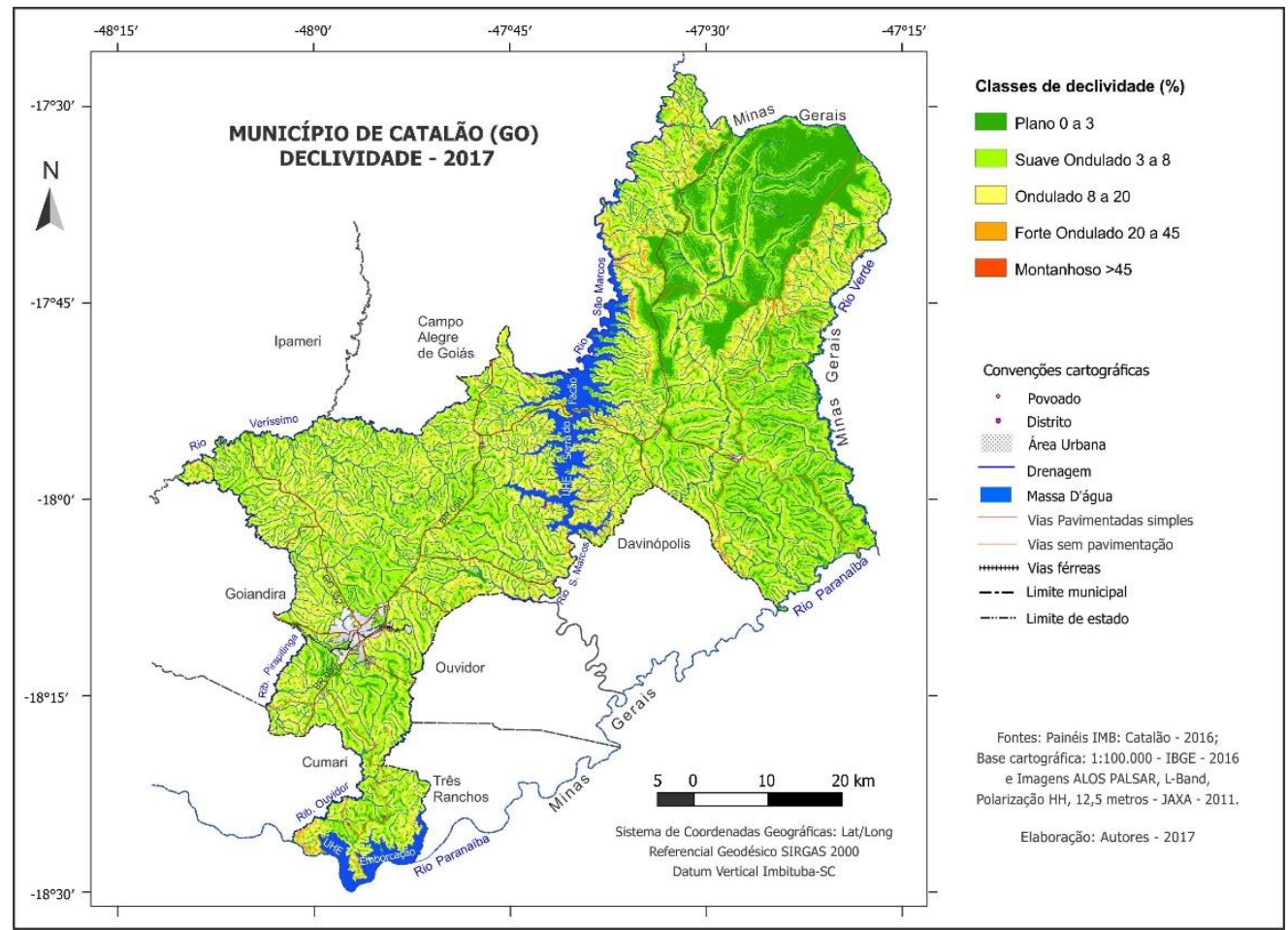

Figura 5 - Mapa de Declividade do município de Catalão (GO) - 2017.

Fonte: Elaboração dos autores (2017).

O mapeamento de uso da terra e da cobertura vegetal foi elaborado utilizando-se de imagens do Sensor OLI/Landsat8 e com as seguintes categorias agrupadas e quantificadas em percentual: Mata ciliar, Mata de galeria, Palmeiral: 11,34\%, Mata seca semidecidual/sempre-verde: $0,28 \%$, Cerradão: 1,44\%, Cerrado denso/típico com e sem galeria: 0,23\%, Cerrado ralo/rupestre, Campo rupestre/sujo com galeria 19,63\% e campo limpo/rupestre com galeria: 0,08\%, Campo sujo úmido com vereda: 1,78\%; e Campo limpo úmido com vereda: 0,35\%, Cultura agrícola: 25,23\%, Cultura agrícola perene: 0,13\%, Cultura irrigada por pivô central:1,44\%. As atividades agrícolas somaram 26,80\%, mas permanecem em segundo lugar no total de área. Já a pastagem cultivada, ocupando 27,65\%, é a atividade com maior percentual de intervenção antrópica. A Silvicultura (Pinus, Eucalyptus ou Seringueira) ocupa 4,02\% da área. A influência urbana é de 0,97\%; a mineração ocupa 0,30\% e a massa d'água $5,12 \%$. No Quadro 4 a seguir estão os percentuais ocupados por cada classe com suas respectivas áreas.

Quadro 4 - Área ocupada pelas classes uso da terra e cobertura vegetal nativa - 2017.

\begin{tabular}{lccc}
\hline \multicolumn{1}{c}{ Classes uso da terra e cobertura vegetal nativa } & \multicolumn{3}{c}{ Área } \\
\hline Mata ciliar, Mata de galeria, Palmeiral - Fa & 433,56 & $43.355,5198$ & 11,34 \\
Mata seca semidecidual/sempre-verde - Fs & 10,70 & $1.069,97475$ & 0,28 \\
Cerradão - Sd 8 & 54,89 & $5.488,82475$ & 1,44 \\
Cerrado denso/típico com e sem galeria - Sas e Saf & 8,74 & 874,29775 & 0,23
\end{tabular}


Cerrado ralo/rupestre, Campo rupestre/sujo com galeria - Spf

Campo limpo/rupestre com galeria - Sgf e Sgs

Campo sujo úmido com Vereda - Pa1

Campo limpo úmido com Vereda - Pa2

Cultura agrícola - Ac - 1

Cultura agrícola perene - Ac1

Cultura irrigada por pivô central - Ac2

Pastagem cultivada - Ap

Silvicultura (Pinus, Eucalyptus ou Seringueira) - R

Influência Urbana - Iu

Mineração - Im

Massa D’água - Água

\begin{tabular}{rrr}
750,39 & $75.038,6698$ & 19,63 \\
3,10 & 309,76775 & 0,08 \\
68,04 & $6.803,92975$ & 1,78 \\
13,42 & $1.341,79875$ & 0,35 \\
964,30 & $96.430,4038$ & 25,23 \\
4,91 & 491,31375 & 0,13 \\
54,86 & $5.486,48375$ & 1,44 \\
$1.056,86$ & 105686,19 & 27,65 \\
153,50 & $15.350,0028$ & 4,02 \\
37,11 & $3.710,62775$ & 0,97 \\
11,37 & 1137,39075 & 0,30 \\
195,71 & $19.571,1048$ & 5,12 \\
\hline $\mathbf{8 2 1 , 4 6 3}$ & $\mathbf{3 8 2 . 1 4 6 , 3 0 0}$ & $\mathbf{1 0 0 , 0 0}$
\end{tabular}

Total

Fonte: Mapa de uso da terra e cobertura vegetal nativa - 2017.

Elaboração: Autores (2017).

As atividades agrícolas e de pastagem cultivada ocupam juntas o maior percentual de intervenção antrópica do município, conforme mostra o mapeamento de uso da terra e cobertura vegetal nativa. A classe pastagem cultivada é predominante representando 27,65\% da área, como apresentado no Quadro 4 e na Figura 6. A classe pastagem plantada mantém sua tendência de maior proporção de ocupação, e se comparada com dados do MMA (2015), a classe pastagem plantada em 2013 já ocupava $(29,5 \%)$ de todo o Cerrado.

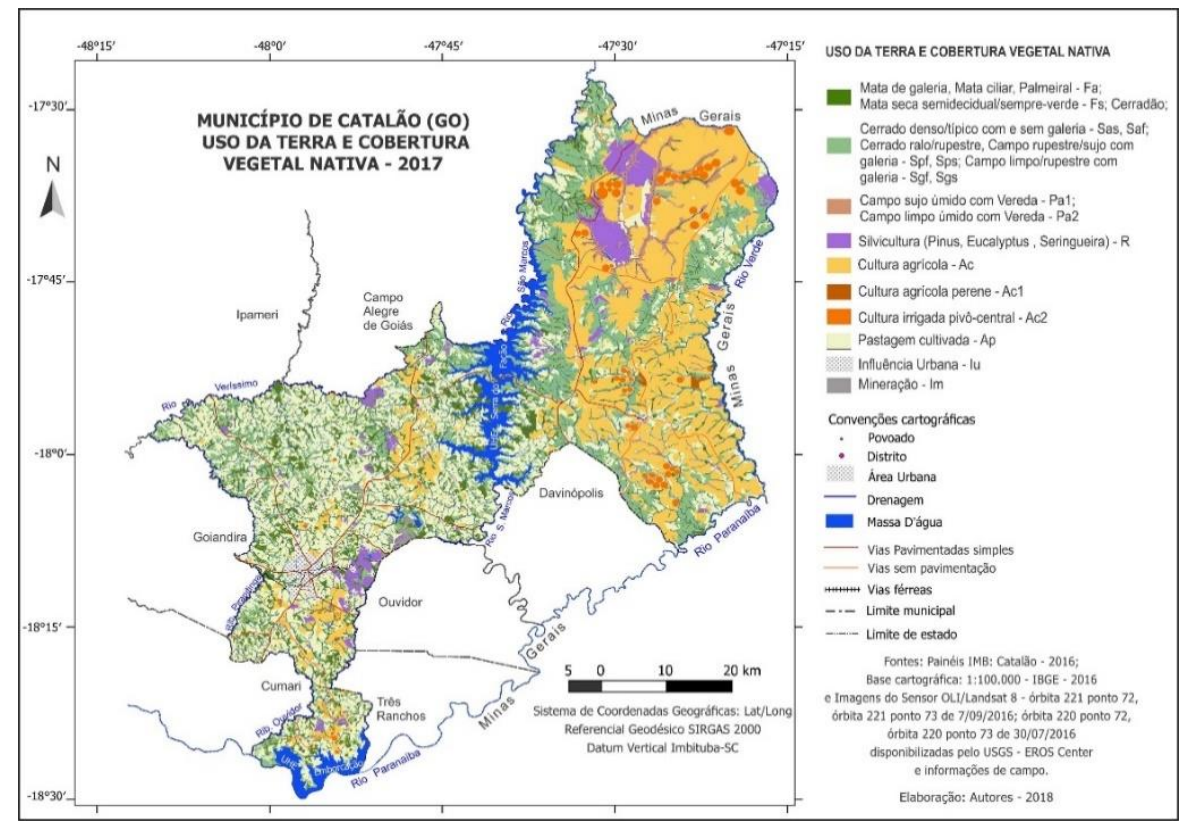

Figura 6 - Mapa de Uso da terra e cobertura vegetal nativa - 2017.

Fonte: Elaboração dos autores (2018). 
$\mathrm{O}$ uso das terras agrícolas sem planejamento adequado tem gerado consequências ambientais negativas. Certamente, o estudo da capacidade de uso das terras proporciona suporte ao planejamento do uso das terras de forma racional, pois auxilia nas análises em ambientes rurais.

Lepsch (2015) propõe que as terras sejam classificadas por identificação do grau de capacidade de uso, com intensidade mínima a máxima, sendo que quanto maior a limitação, menor a intensidade de uso. No mapeamento realizado sobre a capacidade de uso da terra de Catalão, foram identificadas sete classes, conforme mostram o Quadro 5 e a Figura 7.

Quadro 5 - Áreas das classes de capacidade de uso da terra no município de Catalão (GO) - 2017.

\begin{tabular}{crrr}
\hline Classe & \multicolumn{3}{c}{ Área } \\
Kma & \multicolumn{1}{c}{ Ha } \\
\hline I & 9,39 & 938,68 & 0,27 \\
II & $1.986,18$ & 198618,37 & 51,88 \\
III & 676,91 & 67690,51 & 17,70 \\
IV & 138,42 & 13841,53 & 3,64 \\
VI & 501,64 & 50163,64 & 13,12 \\
VII & 107,28 & 10728,16 & 2,83 \\
VIII & 203,57 & 20356,63 & 5,34 \\
Massa d'água & 175,30 & 17530,36 & 4,60 \\
Influência urbana & 22,78 & 2278,42 & 0,62 \\
Total & $\mathbf{3 . 8 2 1 , 4 6}$ & $\mathbf{3 8 2 . 1 4 6 , 3 0}$ & $\mathbf{1 0 0 , 0 0}$ \\
\hline
\end{tabular}

Fonte: Mapa de capacidade de uso da terra município de Catalão (GO) - 2017.

Elaboração: Autores (2018).

As terras classificadas na Classe I são passíveis de cultivos intensivos e sem problemas especiais de conservação e/ou melhoramentos químicos. Já as terras classificadas na classe II possuem pequenas limitações, com problemas simples de conservação.

As terras classificadas na classe III possuem características que reduzem ou limitam a preferência dos cultivos, ou seja, necessitam de práticas complexas de conservação. Desta maneira, as classes I, II e III, somando 69,85\% da área da pesquisa, estão aptas à agricultura, desde que resguardadas as de áreas de preservação permanente.

As terras de classe IV possuem 3,64\% do total de área e apresentam limitações que são ainda mais severas para cultivos intensivos, se cultivadas com lavouras anuais eventualmente ou com cultivos perenes protetores para conservação do solo.

Desta forma, as culturas anuais são adequadas para as classes I a III e apenas são possíveis na classe IV ocasionalmente como, por exemplo, na implantação de culturas perenes ou na reforma das pastagens.

Já as terras da classe VI possuem limitações muito severas; são impróprias para cultivos, por isso pastagens e reflorestamento são os usos recomendados.

As terras da classe VII possuem limitações: apresentam problemas complexos de conservação de solo e são impróprias para culturas. Pastagens e reflorestamentos são os usos indicados. 
Por fim, as terras da classe VIII são impróprias para lavouras, pastagens e reflorestamento. Podem ser utilizadas apenas para a proteção da fauna e da flora.

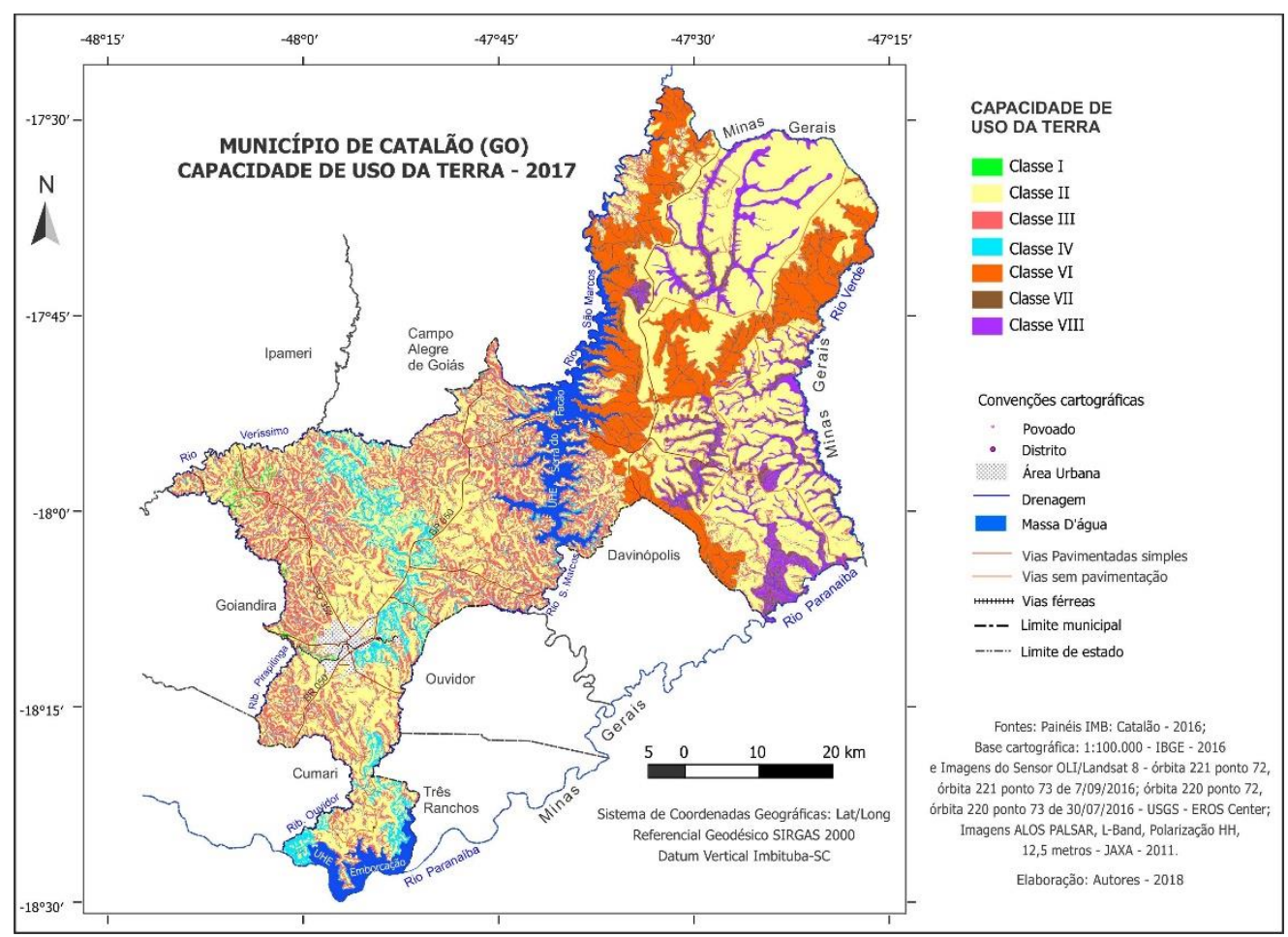

Figura 7 - Mapa de Capacidade de uso da terra - 2017

Fonte: Elaboração dos autores (2018)

O uso da terra do município de Catalão é bastante diverso, assim é essencial ter informações de um mapa de uso potencial das terras para melhor utilizar seus recursos naturais. O mapeamento identificou que a classe pastagem cultivada conta com $27,65 \%$ da área sendo a maior ocupação e que esta classe é a que mais impacta as áreas de APPs - em 13,33\%. Quanto à subutilização em solos, nos chama atenção a classe II no Chapadão, ocupada por silvicultura e por pastagem na porção centro-sul do município. Ainda, o cultivo concentrado de silvicultura e culturas anais no Chapadão, extremamente próximo às nascentes e a áreas úmidas e de veredas, apresenta maiores riscos ambientais devido à fragilidade desses ambientes naturais.

Há que se considerar as potencialidades dos recursos naturais, as fragilidades dos sistemas ambientais naturais, a possibilidade de recuperação dos ambientes degradados, para identificar, com o mapa de uso potencial das terras, como está ordenado o uso da terra, servindo assim como suporte para adequar melhor o uso e manejo da terra. A seguir, o Quadro 6 traz as classes de uso potencial das terras e suas áreas: 
Quadro 6 - Área das classes de uso potencial das terras.

\begin{tabular}{lrrr}
\hline \multicolumn{1}{c}{ Classe } & \multicolumn{3}{c}{ Área } \\
\\
\end{tabular}

Fonte: Mapa de capacidade de uso da terra, APPs e Mapa de uso da terra e cobertura vegetal nativo município de Catalão (GO) - 2017.

Elaboração: Autores (2017).

O Quadro 6 mostra as áreas das classes de uso potencial das terras no município de Catalão (GO). Do total das terras, 40,69\% são recomendadas para agricultura, $11,84 \%$ para pastagens, 3,32\% para reflorestamento e 38,33\% para preservação. Já na classe de silvicultura, o cruzamento do mapa de uso da terra e de cobertura vegetal nativa com o de capacidade das terras, revelou que $2,74 \%$ desta classe está subutilizada, pois ocupa a classe II, podendo ser realocada para classe IV ou Florestamento espécie exótica.

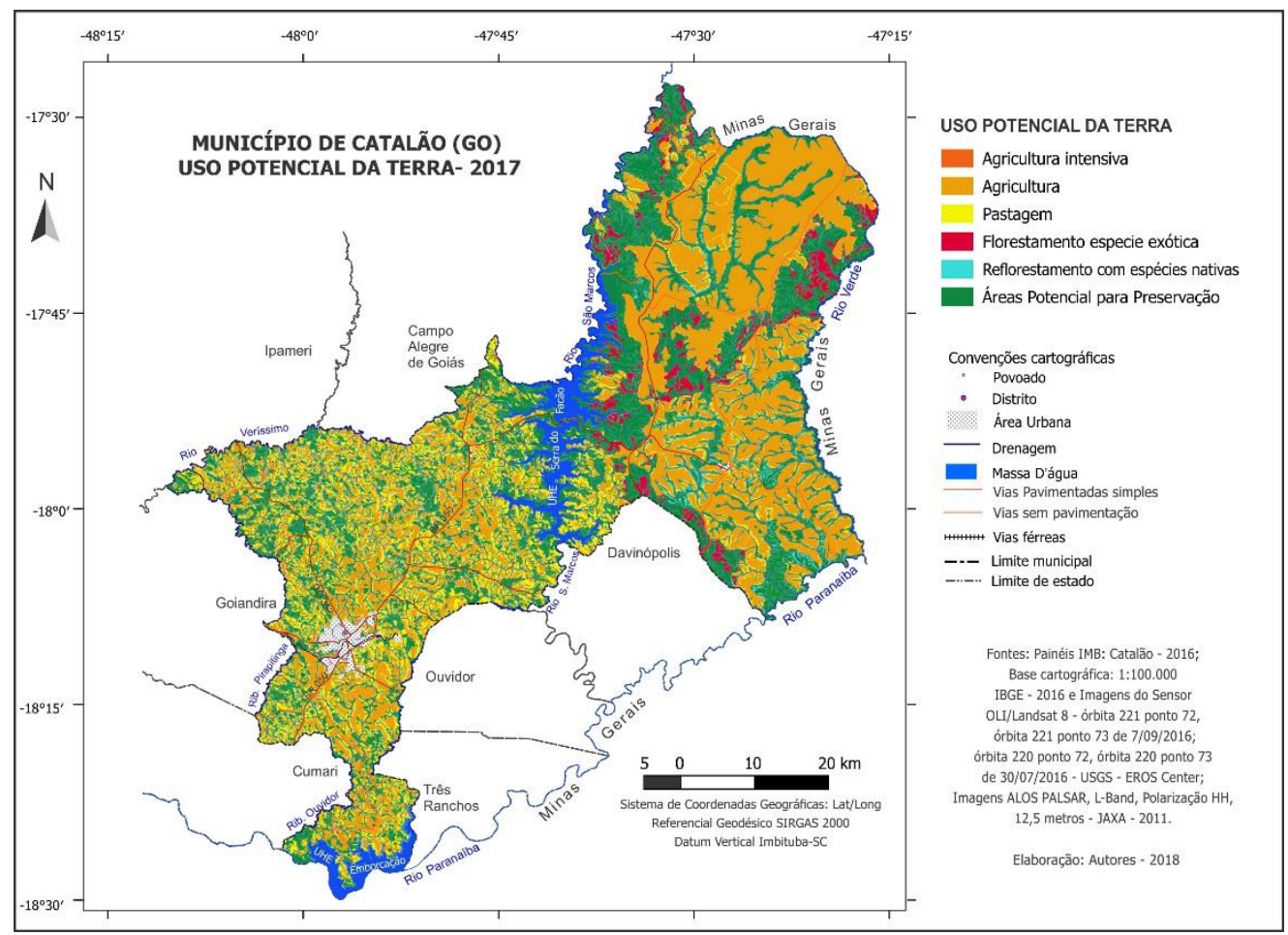

Figura 8 - Mapa de Uso potencial das terras para o município de Catalão (GO) - 2017.

Fonte: Elaboração dos autores (2018). 
O Quadro 7 traz a correlação entre uso potencial das terras e uso da terra e da cobertura vegetal nativa. As áreas de uso potencial das terras têm um maior percentual das classes, conforme o uso potencial das terras indicado para a agricultura $(22,90 \%)$.

Quadro 7 - Correlação entre uso potencial das terras, uso da terra e cobertura vegetal nativa.

\begin{tabular}{|c|c|c|c|c|c|c|c|c|}
\hline \multirow{3}{*}{ Classes } & 1 & 2 & 3 & 4 & 5 & 6 & 7 & 8 \\
\hline & & & & & & & & \\
\hline & $\%$ & $\%$ & $\%$ & $\%$ & $\%$ & $\%$ & $\%$ & $\%$ \\
\hline Cultura agrícola & 0,01 & 21,43 & 1,57 & 0,62 & 0,26 & 0,76 & - & 0,01 \\
\hline Cultura agrícola perene & - & 0,10 & 0,01 & 0,00 & 0,00 & 0,01 & - & - \\
\hline Massa D'água** & - & 0,34 & 0,21 & 0,09 & 0,01 & 0,08 & 4,30 & - \\
\hline Influência Urbana** & 0,01 & 0,39 & 0,04 & - & - & 0,00 & - & 0,51 \\
\hline $\begin{array}{l}\text { Cerrado denso/típico com e sem galeria; Cerrado ralo/rupestre, Campo } \\
\text { rupestre/sujo com galeria; Campo limpo/rupestre com galeria* }\end{array}$ & 0,03 & 4,76 & 3,91 & 7,79 & 1,46 & 1,04 & 0,07 & 0,02 \\
\hline Mineração & - & 0,17 & 0,09 & - & - & - & - & - \\
\hline Cultura irrigada pivô-central & - & 1,36 & 0,05 & 0,00 & 0,00 & 0,01 & - & - \\
\hline Pastagem cultivada & 0,13 & 14,01 & 7,39 & 2,26 & 0,46 & 0,65 & 0,17 & 0,05 \\
\hline Silvicultura & - & 2,74 & 0,57 & 0,36 & 0,05 & 0,04 & - & - \\
\hline $\begin{array}{l}\text { Mata ciliar, Mata de galeria, Palmeiral; Mata seca } \\
\text { semidecidual/sempre-verde; Cerradão* }\end{array}$ & 0,07 & 5,47 & 3,58 & 1,67 & 0,35 & 1,02 & 0,03 & 0,02 \\
\hline Campo sujo úmido com Vereda; Campo limpo úmido com Vereda* & - & 0,30 & 0,04 & 0,17 & 0,18 & 1,44 & - & - \\
\hline
\end{tabular}

1 Agricultura intensiva; 2 Agricultura; 3 Pastagem; 4 Florestamento espécie exótica; 5 Reflorestamento com espécies nativas; 6 Áreas Potencial para Preservação; 7 Massa d'água; 8 Área Urbana.

*Classes potencial preservação. ** Classes áreas urbanas e de corpos d'água, não se aplica.

Fonte: Mapa de capacidade de uso da terra, Apps e Mapa de uso da terra e cobertura vegetal nativa do município de Catalão (GO) - 2017.

Elaboração: Autores (2018)

Na correlação entre uso potencial das terras, uso da terra e cobertura vegetal nativa e conflito de uso em áreas de APPs, as análises nos mostram ainda que no conflito de uso em áreas de APPs no município de Catalão (GO), a classe de Pastagem cultivada ocupa 13,33\%, seguida pela classe Cultura agrícola com $8,43 \%$.

Diante disso, as informações fornecidas pelo mapeamento do uso potencial das terras do município contribuem para adequar a vocação agropecuária e para a indicação de tecnologias adequadas, do risco de erosão, do controle de impactos ambientais, respeitando ainda a legislação ambiental. É importante salientar que estudos complementares são necessários para melhor compreender o processo dos sistemas ambientais, a conservação ambiental e a utilização dos recursos naturais, visando o uso e a manutenção da qualidade dos ambientes naturais. 


\section{CONSIDERAÇÕES FINAIS}

Com o início de atividades intensivas em áreas do Cerrado, desde o século XX, predominantemente nos relevos aplainados, atividades da agricultura e de pecuária intensiva ocasionaram a deterioração ambiental em extensas áreas do Bioma, devido à falta de ações de manejo adequado. Nesse cenário, Catalão (GO) também foi atingida pelo avanço das agroindústrias, dos agronegócios e do setor de mineração.

As informações e as análises dos dados não-espaciais, espaciais por intermédio do geoprocessamento e da utilização de instrumentos de Sensoriamento Remoto e Sistema de Informações Geográficas, foram satisfatórias pois permitiram a elaboração de um diagnóstico do município. O planejamento do uso potencial da terra, a inclusão de técnicas de sensoriamento remoto para interpretação, aliado ao uso do software QGIS e plugins, possibilitou o uso de procedimentos de vetorização, como o uso de mesa digitalizadora digital e caneta interativa, que permitiram a redução do tempo de vetorização das classes uso da terra.

Os mapeamentos, as visitas a campo e as análises apontam a necessidade de adequar o manejo do uso da terra no município de Catalão, quanto a classe de Pastagem cultivada, que ocupou 13,33\%, seguida pela classe Cultura agrícola com 8,43\%, sendo áreas de conflito de uso em APP. Também a classe Silvicultura (Pinus, Eucalyptus ou Seringueira) ocupa 1,86\% de áreas de APPs, e as áreas de veredas Chapadão necessitam de um plano de manejo, pois são frágeis e apresentam baixa resiliência a usos intensivos como represamento para irrigação com pivôs de central.

Quanto ao uso das terras, o mapa de capacidade de uso das terras aponta que as classes I, II e III, correspondendo a 69,85\% da área da pesquisa, estão aptas à agricultura, desde que resguardadas as de áreas de preservação permanente. Já as terras de classe IV representam 3,64\% do total de área com limitações que são ainda mais severas para cultivos. As terras classe VI com $13,12 \%$ da área são recomendadas para pastagens e reflorestamento. A classe VII, indicada para reflorestamentos, conta com $2,83 \%$ do total da área. As terras da classe VIII são indicadas para a fauna e flora com $5,34 \%$.

Deste modo, o mapa elaborado acerca do uso potencial das terras considerou as potencialidades dos recursos naturais, as fragilidades dos sistemas ambientais naturais e de recuperação dos ambientes degradados. As classes de uso potencial das terras no município de Catalão salientam que do total das terras recomendadas, 40,69\% são para agricultura, 11,84\% são aconselhadas para pastagens, 3,32\% para reflorestamento e 38,33\% para preservação.

Por conseguinte, o mapa de uso potencial das terras para o município de Catalão (GO), elaborado neste trabalho, dá ao planejador e ao gestor subsídios para a distribuição espacial do 
potencial de uso de suas terras, pois, com ele, além da avaliação da capacidade de uso das terras, há a demonstração de que ainda é possível indicar os critérios, as alternativas de usos e a conservação.

Os mapas produzidos neste trabalho servem como base para realizar o planejamento de uso racional das terras, contribuindo para o manejo e para a conservação ambiental no município de Catalão (GO) e também servirão como fonte de aperfeiçoamento.

\section{REFERÊNCIAS}

AB'SÁBER, A. N. Os domínios da natureza no Brasil: potencialidades paisagísticas. 1. ed. São Paulo: Ateliê Editorial, 2005. 160p.

ANDERSON MEDEIROS. Consultor em geotecnologias. QGIS. Disponível em: <http://andersonmedeiros.com/blogs-sobre-geotecnologias/>. Acesso em: 10 set. 2016.

ASSAD, E. D.; SANO, E. E. Sistema de informações geográficas: aplicações na agricultura. 2. ed. Brasília: EMPRAPA, 1998. 25p.

ASSAD, M. L. L.; HAMADA, E.; CAVALIERI, A. Sistemas de informações geográficas na avaliação de terras para agricultura. In: ASSAD, E. D.; SANO, E. E. (Orgs.). Sistemas de informações geográficas: aplicações na agricultura. Brasília: EMPRAPA, 1998.

BRASIL. Ministério do Meio Ambiente. Mapeamento do Uso e Cobertura do Cerrado: Projeto TerraClass Cerrado 2013. Brasília: MMA, 2015. 67p.

Lei $\mathrm{n}^{\mathrm{0}} \mathbf{1 2 . 6 5 1}$ de 25 de maio de 2012. Disponível em:

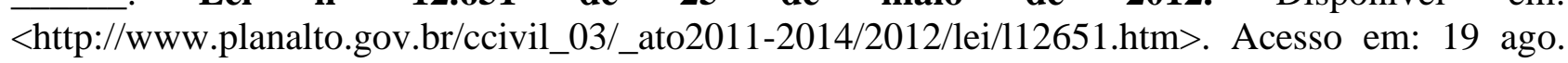
2017.

.Ministério das Minas e Energia. Projeto RADAMBRASIL: Levantamento de Recursos Naturais. Rio de Janeiro: Divisão de publicação do projeto RADAMBRASIL, 1983, (Folha SE 22 Goiânia, vol. 31). (mapas, 1:250.000).

. Resolução CONAMA No 302 de 20 de março de 2002. Disponível em:< http://pesquisa.in.gov.br/imprensa/jsp/visualiza/index.jsp?data=13/05/2002\&jornal=1\&pagina=67\& totalArquivos=96>. Acesso em: 19 ago. 2017.

Resolução CONAMA $\mathbf{N}^{\circ} \mathbf{3 0 3}$ de 20 de março de 2002. Disponível em: <http://pesquisa.in.gov.br/imprensa/jsp/visualiza/index.jsp?data=13/05/2002\&jornal=1\&pagina=68 \&totalArquivos=96> . Acesso em: 19 ago. 2017.

BOSSLE. R. C. QGIS do ABC ao XYZ. 1. ed. São José dos Pinhais: Íthala, 2016. 288p.

BRITO, J. L. S. Adequação do Uso da Terra na Bacia do Ribeirão Bom Jardim: ensaio de geoprocessamento. 2001. 61 f. Tese (Doutorado em Geografia Física) - Faculdade de Filosofia, Letras e Ciências Humanas, Universidade de São Paulo, 2001.

DIRETORIA DE SERVIÇO GEOGRÁFICO (DSG). Banco de Dados Geográficos do Exército. Versão 3.0. 2013. Disponível em: <http://www.geoportal.eb.mil.br/mediador/>. Acesso em: 16 out. 2016. 
EMATER - Agência Goiana de Assistência Técnica, Extensão Rural e Pesquisa Agropecuária. Classes de solos dos municípios goianos - 2016. 2016.

EMBRAPA. Empresa brasileira de pesquisa agropecuária. Reunião Técnica de Levantamento de Solos. 1. ed. Rio de Janeiro: SNLCS, 1979. 83p.

. Empresa brasileira de pesquisa agropecuária. Sistema brasileiro de classificação de solos. 3. ed. Rio de Janeiro: Embrapa Informação tecnológica, 2013. 353p.

EORC/JAXA - Earth Observation Research Center/Japan Aerospace Exploration Agency. 2011. Alos Palsar. Disponível em: <http://www.eorc.jaxa.jp/ALOS/en/about/palsar.htm>. Acesso em: 08 jan. 2018.

FERREIRA, I. M. O Afogar das Veredas: uma análise comparativa espacial e temporal das Veredas do Chapadão de Catalão (GO). 2003. 242 f. Tese (Doutorado em Geografia) - Universidade Estadual Paulista, Rio Claro, 2003.

GEOSABER. Geociências e Geotecnologias livres. <https://geosaber.blogspot.com>. Acesso em: 12 jun. 2016.

GOIÁS, Lei $\mathbf{n}^{\mathbf{0}}$ 18.104, de 18 de Julho de 2013. Disponível em: <http://www.gabinetecivil.goias.gov.br/leis_ordinarias/2013/lei_18104.htm>. Acesso em: 22 jun. 2016.

GRASS DEVELOPMENT TEAM, 2016. Geographic Resources Analysis Support System (GRASS) Software, Version 7.0. Open Source Geospatial Foundation. Electronic document. Disponível em: <http://grass.osgeo.org>. Acesso em: 18 nov. 2016.

HASUI, Y. Sistema orogênico Tocantins. In: HASUI, Y. (Org.). Geologia do Brasil. São Paulo: Beca, 2012. p. 289-330.

INSTITUTO BRASILEIRO DE GEOGRAFIA E ESTATÍSTICA. Censo demográfico Goiás. Municípios do Estado de Goiás. Rio de Janeiro: IBGE, 1970. Disponível em: $<$ https://biblioteca.ibge.gov.br/visualizacao/periodicos/69/cd_1970_v1_t23_go.pdf $>$. Acesso em: 08 jan. 2018.

- Censo demográfico. Municípios do Estado de Goiás. Rio de Janeiro: IBGE, 1980, 1991, $\overline{2000}$ e 2010. Disponível em: < https://sidra.ibge.gov.br>. Acesso em: 06 jan. 2018.

. Enciclopédia dos municípios brasileiros. In: Catalão (GO). Rio de Janeiro: IBGE, 1958. v. 36. p. 113-119

. Manuais técnicos em geociências n⿳07 - Manual Técnico de Uso da Terra. 3. ed. Rio de Janeiro, 199, 177p.

- Panorama: território, ambiente e população estimada de Catalão, 2018. Rio de Janeiro: IBGE, Disponível em: <https://cidades.ibge.gov.br/brasil/go/catalao/panorama>. Acesso em: 08 dez. 2018.

. Sistema IBGE de Recuperação Automática: SIDRA. Rio de Janeiro: IBGE, Disponível em: $<$ https://sidra.ibge.gov.br>. Acesso em: 06 jan. 2018. 
INSTITUTO MAURO BORGES DE ESTATÍSTICAS E ESTUDOS SOCIOECONÔMICOS. Atlas do Estado de Goiás - 2014. Goiânia: Secretaria de Estado de Gestão e Planejamento de Goiás. 2014. 98p.
Painéis
IMB:
Catalão.
2016.
Disponível
em:

$\overline{<\mathrm{http}}$ //www.imb.go.gov.br/pub/paineismunicipais/00-Catal\%C3\%A3o201612.pdf>. Acesso em: 13 nov. 2017.

INSTITUTO NACIONAL DE METEOROLOGIA (INMET). Normal climatológica de 1981-

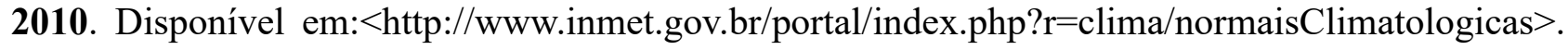
Acesso em: 3 abr. 2018.

KALBERER, P.; MOTTA, L; WALKER, M. Open Layers plugin for QGIS. Disponível em: <http://hub.qgis.org/projects/openlayers>. Acesso em: 18 nov. 2016.

KLEIN, P. B. W. A evolução do uso do solo e suas consequências para o meio ambiente na região do Complexo Ultramáfico-Alcalino-Carbonático de Catalão I. 1996. 101 f. Dissertação (Mestrado em Geologia) - Universidade de Brasília, Brasília, 1996.

Geoquímica de rocha total, geocronologia de U-Pb e geologia isotópica de $\mathrm{Sm}$-Nd das rochas ortognáissicas e unidades litológicas associadas da região Ipameri-Catalão (Goiás). 2008. 183 f. Tese (Doutorado em Geologia) - Universidade de Brasília, Brasília, 2008.

KÖPPEN, W.; GEIGER, R. Klima der Erde (Climate of the earth). 1954. Wall Map 1:16 Mill. Klett-Perthes, Gotha. Disponível em: <http://koeppen-geiger.vuwien.ac.at/pics/Geiger_1954_Map.jpg> Acesso em: 20 mar. 2018.

LEPSCH, I. F.; BELLINAZZI Jr., R.; BERTOLINI, D.; ESPÍNDOLA, C. R. Manual para levantamento utilitário do meio físico e classificação de terras no sistema de capacidade de uso. 4. ed. Campinas: Sociedade Brasileira de Ciência do Solo, 1991. 175p.

LEPSCH, I. F.; ESPÍNDOLA, C. R.; VISCHI FILHO; O. J. HERNANI, L. C.; SIQUEIRA, D. S. Manual para levantamento utilitário e classificação de terras no sistema de capacidade de uso. 5. ed. Viçosa: Sociedade Brasileira de Ciência do Solo, 2015. 170p.

LEPSCH, I. F. Formação e Conservação dos Solos. 1. ed. São Paulo: Oficina de Textos. 2002. $178 \mathrm{p}$.

LIBAULT, C. O. A. Os quatro níveis da pesquisa geográfica. Métodos em questão. 1. ed. São Paulo: USP/IG, 1971. 14p.

MACROZAEE-GO. Macrozoneamento Agroecológico e Econômico do Estado de Goiás. 2014. Disponível em: <http://www.sieg.go.gov.br/siegdownloads>. Acesso em: 13 nov. 2017.

MENDES, E. P. P. A produção rural familiar em Goiás: as comunidades rurais no município de Catalão. 2005. 294 f. Tese (Doutorado em Geografia) - Faculdade de Ciências e Tecnologia, Universidade Estadual Paulista, Presidente Prudente, 2005.

MENDES, L. S. Avaliação das áreas potenciais para preservação ambiental e áreas de conflito na Bacia Hidrográfica do Ribeirão São Lourenço Ituiutaba/MG. 2016. 92 f. Dissertação (Mestrado em Meio Ambiente e Qualidade Ambiental), Universidade Federal de Uberlândia, Uberlândia, 2016. 
MIRANDA, J. I. Fundamentos de Sistemas de Informações Geográficas. 4. ed. Brasília: Embrapa Informação Tecnológica, 2005. 399p.

MMA. Mapeamento do Uso e Cobertura do Cerrado: Projeto TerraClass Cerrado 2013 / MMA / SBF. Brasília: MMA, 2015. 67p.

Levantamento dos remanescentes da cobertura vegetal dos biomas brasileiros. Ministério do Meio Ambiente, Secretaria de Biodiversidade e Florestas, Brasília. 2007. Disponível em: <http://www.mma.gov.br/portalbio>. Acesso em: 6 nov. 2017.

MOTTA, L. Gimp Selection Feature Plugin QGIS. Disponível em: $<$ https://github.com/lmotta/gimpselectionfeature_plugin >. Acesso em: 18 nov. 2017.

NIMER, E. Descrição, análise e interpretação conceitual do sistema de classificação de climas de C.W. Thornthwaite. Revista Brasileira de Geografia, Rio de Janeiro, v. 39, p. 87-109, 1977.

PROBIO - Projeto de Conservação e Utilização Sustentável da Diversidade Biológica Brasileira. Levantamento dos remanescentes da cobertura vegetal dos biomas brasileiros. Disponível em: <http://www.mma.gov.br/portalbio> Acesso em: 6 nov. 2017.

PROCESSAMENTO DIGITAL. QGIS. HEX Tecnologias Geoespaciais. Disponível em: < http://www.processamentodigital.com.br/category/tutoriais/qgis>. Acesso em: 6 ago. 2016.

RADAMBRASIL. Vetores pedologia. Rio de Janeiro: Divisão de publicação do projeto RADAMBRASIL, 2016, (Folha SE 22 Goiânia). (mapas, 1:250.000). Disponível em: <https://mapas.ibge.gov.br/bases-e-referenciais/bases-cartograficas/cartas>. Acesso em: $12 \mathrm{dez}$. 2017.

- Vetores pedologia. Rio de Janeiro: Divisão de publicação do projeto RADAMBRASIL, 2016, (Folha SE 23 Belo Horizonte). (mapas, 1:250.000). Disponível em: <https://mapas.ibge.gov.br/bases-e-referenciais/bases-cartograficas/cartas>. Acesso em: $12 \mathrm{dez}$. 2017.

QGIS DEVELOPMENT TEAM, 2016. QGIS Geographic Information System. Open Source Geospatial Foundation Project. Disponível em: 〈http://qgis.osgeo.org>. Acesso em: 18 nov. 2016.

RAMALHO FILHO, A.; PEREIRA, E. G.; BEEK, K. J. Sistema de avaliação da aptidão agrícola das terras. 1. ed. Brasília: SUPLAN/EMBRAPA/SNLCS, 1978. 70p.

RIBEIRO, J. F.; WALTER, B. M. T. Fitofisionomias do bioma Cerrado. In: SANO, S. M.; ALMEIDA, S. P; RIBEIRO, J. F. (Eds). Cerrado: ambiente e flora. Planaltina: Editora Embrapa Cerrados, 1998. p. 89-166.

ROSA, R. O uso de SIG's para o zoneamento: uma abordagem metodológica. 1995. 214 f. Tese (Doutorado em Geografia) - Faculdade de Filosofia, Letras e Ciências Humanas, Universidade de São Paulo, 1995.

. Introdução ao Sensoriamento Remoto. 5. ed. Uberlândia: EDUFU, 2009. 238p.

. Análise espacial em Geografia. Revista da ANPEGE, v. 7, n. 1, p. 275-289, 2011. 
ROSA, R.; BRITO, J. L. S. Introdução ao Geoprocessamento: Sistema de Informações Geográficas. Uberlândia, 1996. 108p.

ROSS, J. L. S. Landforms and environmental planning: potentialities and fragilities. Revista do Departamento de Geografia, USP, Volume Especial 30 Anos, p. 38-51, 2012.

SANTOS, H. G.; JACOMINE, P. K. T.; ANJOS, L. H. C.; OLIVEIRA, V. A.; LUMBRERAS, J. F.; COELHO, M. R.; ALMEIDA, J. A.; CUNHA, T. J. F.; OLIVEIRA, J. B. Sistema brasileiro de classificação de solos - SiBCS. 3. ed. Brasília: Embrapa, 2013. 353p.

SANO, E. E.; ROSA, R.; BRITO, J. L. S.; FERREIRA, L. G. Mapeamento de cobertura vegetal do bioma Cerrado: estratégias e resultados. 1. ed. Planaltina: Embrapa Cerrados, 2007. 33p.

SEFAC. Plano de Conservação e Uso do Entorno do Reservatório da UHE Serra do Facão PACUERA. $2009 . \quad$ Disponível em: $<$ http://www.sefac.com.br/index.php?arq=pacuera_material_down>. Acesso em: 10 dez. 2017. . Adequação do Plano de Conservação e Uso do Entorno do Reservatório da UHE

Serra do Facão - PACUERA. 2016. Disponível em:
$<$ http://www.sefac.com.br/index.php?arq=pacuera_material_down>. Acesso em: 10 dez. 2017.

SIEG. Base Cartográfica e mapas temáticos de Goiás. Disponível em: <www.sieg.go.gov.br>. Acesso em: 13 nov. 2017.

SILVA, A. S.; GUSSON, M. C.; ROSA, R. Caracterização, análise do uso da terra e cobertura vegetal nativa da bacia hidrográfica do ribeirão São Domingos, Catalão, (GO). In: SIMPÓSIO BRASILEIRO DE GEOMÁTICA. 4., 2017, Presidente Prudente. Anais... Presidente Prudente: SBG, 2017. p. 232-238.

SILVA, A. S. da. Uso potencial das terras no município de Catalão (GO). 2018. 140 f. Dissertação (Mestrado em Geografia) - Universidade Federal de Uberlândia, Uberlândia, 2018.

WWF - Fundo Mundial para a Natureza: banco de dados. Disponível em: <www.wwf.org.br>. Acesso em: 10 nov. 2006. 